\title{
DIFFERENTIATING DISOBEDIENTS
}

\author{
Chong-Ming Lim
}

CTIVISTS WHO BREAK THE LAW on the basis of their conscientious-
sincere and serious-moral or political convictions (henceforth "consci-
entious disobedients," or simply "disobedients") often (if not always) face the demand to differentiate themselves from "ordinary" criminals whose actions also violate laws but are not undergirded by conscientious convictions. ${ }^{1}$ In general terms, this demand for disobedients to differentiate is not implausible-it serves an important function. Individuals who satisfy it are regarded as having a better (though nonetheless defeasible) claim to both the rights-based protections that are granted for conscientious action and to any putative legal excuse that may exist for conscientious breaches of the law. In practical terms, we have (defeasible) reasons to be-and indeed often are-more forgiving in our responses to and treatment of those whose violations of the law are undergirded by conscientious convictions, compared to those whose violations are not. ${ }^{2}$

1 The category of "conscientious disobedients" partially overlaps with that of "principled disobedients." The former is differentiated on the basis of disobedients' convictions (whether they are conscientious); the latter on disobedients' actions (whether they are concordant with moral or political principles). An individual can be conscientious without being principled, and vice versa. Both categories may include those who behave civilly, uncivilly, directly, or indirectly, among others. For further discussions, see Brownlee, Conscience and Conviction, 18-27; and Delmas, A Duty to Resist, 21-46. For a discussion of how the requirement that disobedients be principled excludes or denigrates a certain class of resisters (especially the "lower class"), see Scott, Weapons of the Weak, 286-303. I set aside the class of individuals whose lawbreaking activity is motivated by basic needs.

The differentiation demand as I construe it differs from the requirement that political activists never engage in any lawbreaking activity. The latter is an implausibly narrow formulation of the differentiation demand and runs counter to the commonly held judgement (in most Western liberal societies) that activists can disobey the law in at least some circumstances without thus being no different from criminals. For further discussions of the differentiation demand, and how accusations of criminality are often used to discredit activists, see Lovell, Crimes of Dissent, 3-10; and Terwindt, When Protest Becomes Crime. For a discussion of how the figure of the criminal (especially as a racialized figure) has come to represent the most menacing enemy, see Davis, "Race and Criminalization."

2 Brownlee, Conscience and Conviction, 7. I do not discuss the grounds for or practical implica- 
In order to satisfy the differentiation demand, it is insufficient for disobedients to simply assert that their disobedience is undergirded by their conscientious convictions. To the extent that disobedients can make such assertions, so can criminals. Even if the disobedients' assertions are true, they do not secure the differentiation in the minds of other people. The differentiation demand concerns how disobedients present themselves and are perceived. It is not about whether their unseen mental states and motivations distinguish them (in some "objective" sense) from others who break the law. That is, the differentiation has to be secured from the perspective of their audience. ${ }^{3}$ Observers - who do not have unmediated access to the "internal" states of disobedients-have to look for indications of disobedients' conscientious convictions. To secure differentiation, disobedients have to show that their appeal to those convictions is not just talk. One way of doing so is to behave in ways that are visibly distinct from those of the criminal and that indicate to others that they indeed conscientiously hold the relevant convictions. ${ }^{4}$

In some cases, the burdens involved in satisfying the differentiation demand may be onerous. These burdens have to be contextualized. Even if citizens and common institutions are prepared to accommodate or tolerate lawbreaking acts that are undergirded by conscientious convictions, they nonetheless have interests in avoiding being strung along by criminals who may falsely assert their possession of such convictions in their attempts to avoid punishment. Here, the thought is that in bearing these burdens, a disobedient shows herself to indeed have conscientious convictions. ${ }^{5}$ Living in accordance with those convictions is so important to her that she is prepared to bear those burdens, and moreover may regard doing so as being on the whole worthwhile. And in bearing those burdens, she makes the conscientiousness of her convictions and actions plain for others to see-and thus differentiates herself from criminals who do not, and who are not prepared to, bear those burdens.

Within both public and philosophical discourse, the differentiation demand

tions of our partiality toward conscientious disobedients in this essay.

3 See Brownlee, "Reply to Critics," 727. Here, I take the audience to be the "general public," broadly construed. This is a simplification - the audience is not a monolith. Depending on which subset of the general public we are concerned with, the differentiation of disobedients from criminals may be either facile or nearly impossible. Some members of the general public may also make the differentiation demand on disobedients in bad faith, in their attempt to preserve the status quo. I set aside these complications for future work.

4 There are other ways of specifying the differentiation demand, without reference to individuals' conscientious convictions. See, for instance, Hannah Arendt's discussion of disobedience, which centers on the public and collective nature of civilly disobedient action (Crises of the Republic, 49-102).

5 This may be so even if she bears the burdens for purely strategic reasons. 
is often understood as setting constraints on the actions that disobedients can engage in. For instance, and most commonly, a disobedient is regarded as falling afoul of this demand when she engages in "radical" actions such as arson, rioting, vandalism, or vigilantism, among others. Such actions are often regarded as failing to communicate the disobedients' conscientious convictions, or even as being incompatible with such convictions. They are regarded not as conscientious disobedience but as mere criminal activity. For instance, the actions of the participants in the 2011 England riots and 2015 Baltimore riots - both protests against alleged police brutality against people of color-were denounced as simply criminal activity. ${ }^{6}$ Similar criticisms have also been made of the 2020 Black Lives Matter protests and riots across the United States. Less radical or destructive actions are often also included within the category of radical actions - for instance, harassing political figures at their residences rather than workplaces, denying political figures service at businesses on the basis of their actions, or even engaging in covert and anonymous cyberattacks. ${ }^{7}$ At the extreme, there are also those who judge any act of disobedience as indistinguishable from, or even worse than, ordinary criminality. ${ }^{8}$ While their specifics vary, these criticisms are unified-they urge us to judge and treat those individuals as criminals who are undeserving of the protections or excuses typically afforded to conscientious disobedients.

In this essay, I argue that in some circumstances the differentiation demand can be satisfied by disobedients who engage in what are typically regarded as radical actions. In practical terms, this means that even disobedients who engage in actions such as arson, rioting, vandalism, or vigilantism can also successfully differentiate themselves from criminals. ${ }^{9}$ The category of conscientious disobedients is potentially more inclusive than has been commonly assumed within public and philosophical discourse. Insofar as we think that conscientious disobedients should be judged and treated differently from criminals, we have reason to judge and treat disobedients who engage in these radical acts of disobedience differently from how we currently do. ${ }^{10}$

6 "House of Commons Hansard Debates for 11 Aug 2011," Publications and Records, UK Parliament, accessed February 19, 2020, https://publications.parliament.uk/pa/cm201011/ cmhansrd/cm110811/debtext/110811-0001.htm; Swaine, Jacobs, and Lewis, "Baltimore Protests Turn into Riots as Mayor Declares State of Emergency.

7 Beinart, "Left Wing Protests Are Crossing the Line"; Cochrane, "Sarah Huckabee Sanders Was Asked to Leave Restaurant over White House Work"; Thompson, "Hacktivism."

8 These are views held by a number of judges. See Brownlee, Conscience and Conviction, 6, 156-58. As I suggest in note 1 , this view is implausible.

9 For a controversial defense of looting as an instrument of political resistance, see Osterweil, In Defense of Looting. 
My argument proceeds as follows. In section 1, I briefly present the core features of Kimberley Brownlee's prominent account of the communicative principle of conscientiousness, which is one of the few systematic specifications and elaborations of the conditions constituting the differentiation demand. Over the next two sections - and partly in response to Brownlee-I articulate and defend two core aspects of my account, which provides a qualified defense of conscientious disobedients. In section 2, I argue that the communicative conditions should be characterized as paradigmatically true of those who show that they act on the basis of conscientious convictions, rather than as necessary and sufficient conditions for having those convictions. In section 3 , I argue that while the conditions serve as practical tests of disobedients' convictions, disobedients' singular or even occasional failure of these tests need not threaten or eliminate their differentiation from criminals. They may still satisfy the differentiation demand if we adopt a holistic assessment of their persons and actions. In section 4, I consider the objection that my account imposes overly stringent constraints on disobedients. I conclude in section 5 .

Before proceeding, two quick clarifications of the scope of my discussions are important. First, I focus on the conscientiousness - sincerity and seriousnessof disobedients' convictions and set aside the issue of their content. ${ }^{11}$ The issues are distinct; an individual may conscientiously hold an abhorrent conviction. Of course, we may very well decide that those who conscientiously hold abhorrent convictions are no better (or perhaps even worse) than criminals. In which case, we may see the differentiation demand as applying only to those who do not hold such convictions. I take no stance on this issue here. I note only that in determining or judging that someone who conscientiously holds an abhorrent conviction is no different from a criminal, we would still need to consider how and whether they (or their actions) have securely indicated that they sincerely and seriously hold those convictions.

Second, I focus narrowly on the differentiation demand. This is distinct from the issue of whether disobedients behave justifiably or permissibly. A disobedient can be adequately differentiated from criminals yet behave impermissibly, or she may fail to satisfy the differentiation demand yet behave permissibly. While there is an extensive literature on the permissibility of disobedience, compara-

the violence in the system. My rehabilitation of disobedients does not rule out these strategies, and may even bolster them. The state's disproportionate response to lawbreakers who are recognized as disobedients may be even more frowned upon (and better galvanize action) than if those lawbreakers were regarded as criminals.

11 For a distinction between conscientiousness thus described and a morally nonneutral idea of conscience, see Brownlee, Conscience and Conviction, 7, 16-17. 
tively much less attention has been directed at the issue of whether by engaging in such actions disobedients provide adequate indication of their conscientious convictions. Indeed, many recent discussions of disobedience-especially those that extend the discussions of defensive ethics to the domain of political action-have tended to argue for the permissibility of radical acts of disobedience without attending to the question of whether those who act permissibly in these ways are adequately differentiated from criminals. ${ }^{12}$ To highlight the distinction, consider how a critic could say of such radical acts that even if they were permissible, those who are genuinely animated by conscientious convictions would not engage in them. This, as should be obvious, is a claim commonly made in public discourse. A further defense of how engaging in such acts does not impugn the conscientiousness of disobedients is thus also necessary.

\section{COMMUNICATIVE CONDITIONS}

In this section, I briefly reconstruct the core components of Kimberley Brownlee's communicative principle of conscientiousness. This paves the way for the development of my account in the following two sections.

According to Brownlee's principle, genuine conviction has a communicative element. A disobedient who does not engage in such communication, and who remains silent, "necessarily casts doubt on the sincerity of [her] conviction." ${ }^{3}$ A disobedient has reason to avoid inviting these doubts, for they may result in her being erroneously treated as a criminal, which often draws attention away from the issue against which she protests. ${ }^{14}$ Brownlee's principle comprises four "communicative" conditions-consistency, universality, non-evasion, and dialogue. The communicative conditions are presented as individually necessary and jointly sufficient for someone to have conscientious conviction. ${ }^{15}$ Taken together, the conditions specify and elaborate the general differentiation de-

12 For recent texts, see Brennan, When All Else Fails; Delmas, A Duty to Resist; Pasternak, "Political Rioting”; and Kapelner, "Revolution against Non-Violent Oppression.” Elsewhere, I argue that activists have good reasons to engage in vandalism (Lim, "Vandalizing Tainted Commemorations").

13 Brownlee, Conscience and Conviction, 29.

14 See Terwindt, When Protest Becomes Crime, 234-36.

15 Brownlee has recharacterized these conditions in response to her critics. The non-evasion and dialogic conditions are now presented as corollaries of the consistency and universality conditions, respectively. This recharacterization does not affect my argument. See Brownlee, "Reply to Critics," 724. 
mand. ${ }^{16}$ When disobedients fail to satisfy the conditions, they accordingly fail to satisfy the differentiation demand. ${ }^{17}$

First, the consistency condition requires consistency among a disobedient's "judgements, motivations and conduct to the best extent that [she is] able." 18 Among other things, she avoids speech and conduct that contradicts her judgments or violates her commitments. Second, the universality condition requires disobedients to universalize their judgments. When they judge something to be pro tanto wrong, they must also judge it to be pro tanto wrong for others in similar circumstances - not just for themselves. For instance, a disobedient should not simply judge that it is wrong for her to participate in (an unjust) war but also that everyone who participates in (such a) war behaves wrongly. ${ }^{19}$

Third, the non-evasion condition requires disobedients to be willing to bear the risks of living in accordance with their convictions. They should not seek to evade the implications of their convictions, especially those arising from their disobedience. Here, Brownlee departs from John Rawls's famous specification of the condition - that individuals should willingly accept being arrested and facing legal punishment. ${ }^{20}$ For Brownlee, all that is required is for disobedients to be willing to accept the risk of being arrested and punished. ${ }^{21}$

Finally, the dialogic condition requires disobedients to "be willing to communicate [their] conviction to others in an effort to engage them in reasoned deliberation about its merits." 22 When disobedients satisfy this condition, they treat others as reasoning agents rather than as those who may be (or are to be)

To preempt an exegetical worry: this characterization does not misunderstand Brownlee's argument. First, Brownlee explicitly presents the conditions as separating conscientious actors from "ordinary offenders [who] are not conscientiously motivated in any deep sense." Second, Brownlee is clear that conscientiousness is a descriptive property. Describing an individual as conscientious is not equivalent to making a moral evaluation of her person or actions. If so, the communicative conditions are not conditions for the justification or permissibility of actions. See Brownlee, Conscience and Conviction, 3-10, 17-18.

Here, I assume that Brownlee's principle is broadly plausible. Challenges to it are, of course, possible. For instance, we may think that conscientiousness requires critical and reflective endorsement such that genuine convictions are distinguished from those that are the result of ideological (or even propagandic) influences. Revisions to the principle do not affect my subsequent discussions.

Brownlee, Conscience and Conviction, 30.

Brownlee, Conscience and Conviction, 34-37. Satisfying the universality condition is, in principle, compatible with relying on the nonuniversalized claim to seek protections for one's conscientious refusal to participate in a given war.

Rawls, $A$ Theory of Justice, 322.

Brownlee, Conscience and Conviction, 37-42.

Brownlee, Conscience and Conviction, 42. 
coerced. Two caveats are important. First, the condition is not overly demanding-it does not require disobedients to succeed in communicating their conviction or persuading their audience; it requires only their willingness to do so. Second, a genuine dialogue is not mere assertion. Participants in a dialogue must be responsive to the possibility that they may be mistaken and ensure that their communication is likely to foster rather than detract from dialogue. ${ }^{23}$

The four conditions are broadly context sensitive. While it is important to satisfy them, doing so does not have conclusive weight. Depending on the context, other considerations - such as those to do with the "burdens of vulnerability, disadvantage, unpopularity, relative power, and the relative costs of communication"-may outweigh the requirement to behave in ways that satisfy the conditions. ${ }^{24}$ In accommodating context sensitivity, Brownlee also accommodates the fact that disobedients may be committed to respecting and furthering other values.

According to Brownlee, three of the four conditions-consistency, non-evasion, and dialogue - have conative elements. They are connected to individuals' actions. Because of these conative elements, the conditions are practically testable. Observers can look at the conduct of disobedients to check whether they satisfy the conditions. This is a more credible way of assessing whether disobedients have and act on the basis of conscientious convictions than simply taking their word for it. ${ }^{25} \mathrm{~A}$ disobedient whose judgments, motivations, and actions are consistent shows that she genuinely has and acts on the basis of conscientious convictions. A disobedient who is non-evasive signals that her assertions about her convictions are not just talk. A disobedient who is willing to engage others in dialogue or to stand up for her convictions in a public way shows, again, the sincerity and seriousness of her convictions. ${ }^{26}$ The universality condition does not have a conative element because it requires only universalized pro tanto judgments. Insofar as such judgments may be outweighed, the all-things-considered judgments on the basis of which individuals act may not reflect (and may indeed deviate from the demands of) their pro tanto judgments.

\section{SHOWING CONSCIENTIOUSNESS}

I begin the articulation of my account by highlighting a distinction, which is often missed in discussions of how disobedients are (or are to be) differentiated from criminals, between having conscientious convictions and showing that

23 Brownlee, Conscience and Conviction, 20, 42-44, 223.

24 Brownlee, Conscience and Conviction, 44.

25 Brownlee, Conscience and Conviction, 30.

26

Brownlee, Conscience and Conviction, 33-43. 
one acts on the basis of such convictions. A brief discussion of the communicative conditions clarifies this distinction.

The communicative conditions may be characterized in two ways. ${ }^{27}$ First, they may be understood as identifying and demarcating the category of those who have conscientious convictions. When disobedients fail to satisfy one or more of these conditions, they do not have conscientious convictions. ${ }^{28}$ Call this Possession. Second, in satisfying the conditions, individuals show others that they act on the basis of conscientious convictions (though whether they have such convictions is, of course, a separate issue). Call this Indication. According to Indication, disobedients' satisfaction of the conditions assuages the doubts of observers about whether they act on the basis of conscientious convictions. ${ }^{29}$ On both Possession and Indication, the conditions are necessary and sufficient.

Possession and Indication are intimately connected. Specifically, Indication succeeds because Possession sketches out a plausible view about what it is to have such convictions in the first place. The distinction and connection between Possession and Indication are crucial. However, Brownlee does not clearly distinguish them in articulating her account, nor does she offer an explicit discussion of their connection. They also appear to be missed by Brownlee's critics. ${ }^{30}$

Indeed, many critics of the communicative principle offer a structurally similar argument centering on the communicative conditions' susceptibility to a range of obvious counterexamples-comprising individuals who fail to satisfy one of the conditions yet who actually have conscientious convictions. For instance, Christopher Cowley offers the counterexample of a committed vegetarian who does not recognize the possibility of her being mistaken about whether eating meat is wrong. Cowley suggests that this case bears structural similarities to the activist Rosa Parks, who disobeyed laws mandating racial segregation. Parks is described as being similarly secure in her conviction that segregation is wrong. In both cases, the individuals are "not open to the possibility of error,"

The characterization of the conditions is distinct from their specification. The latter concerns what the conditions pick out. The former concerns how we understand the nature of the conditions themselves-including, among other things, their function, point, or more broadly, their relationship to the differentiation demand.

Brownlee, Conscience and Conviction, 33, 35, 38, 40, 43.

Thomas E. Hill seems to be among the few critics who explicitly recognize that the communicative conditions can be characterized in different ways. He describes the conditions as those for an individual to have conscientious convictions (mapping on to Possession), and as identifying the convictions that the law should respect and protect. While I suspect that the conditions are not appropriately characterized in the latter way, I do not discuss this issue here. See Hill, "Conscientious Conviction and Conscience." 
yet are very plausibly described as having conscientious convictions. ${ }^{31}$ This is a challenge to Brownlee's claim that such recognition is among the necessary conditions for having conscientious convictions. ${ }^{32}$ Similarly, Candice Delmas provides several counterexamples of individuals who run afoul of the "narrow conception" of conscientiousness that Brownlee sketches yet who actually have conscientious convictions. According to Delmas, a Catholic who engages, before marriage, in various sorts of intimate physical contact short of coitus-thus failing the consistency condition-may nonetheless be conscientiously devout. Someone who fails to satisfy the universality condition in her refusal to pass judgment on women who underwent or plan to undergo abortions may nonetheless have conscientious convictions against abortion. ${ }^{33}$ Cowley and Delmas are not alone; similar arguments are made elsewhere. ${ }^{34}$

These counterexamples are intended to support the position that the communicative conditions are specified too stringently or narrowly and thus deliver extensionally inaccurate verdicts about who has conscientious convictions. If successful-if, that is, the agents to which the counterexamples refer can plausibly be said to have conscientious convictions - they pose a serious challenge to the characterization of the conditions as necessary and sufficient for individuals to have conscientious convictions.

\section{Cowley, "Conscientious Objection and the Limits of Dialogue," 1009.}

32 Brownlee, Conscience and Conviction, 20n9. In response to critics, Brownlee appears to weaken the specification of, and the requirement imposed by, the dialogic condition. Someone like Rosa Parks would count as conscientious if she "would have tried to understand" her opponents' motivations and commitments and if she "would also have sought to see things" from their perspectives. This revision is, however, also susceptible to the kinds of counterexamples raised by her critics; I set it aside (Brownlee, "Reply to Critics," 728).

Delmas also lists, among her examples, the case of an individual raised in a very conservative environment who "might be evasive and non-dialogic as she comes to shed her parents' and peers' views and develops liberal conscientious convictions." She credits Alon Harel as the inspiration for this example. However, this example does not challenge the specification of the communicative conditions. Since the individual in concern has not fully developed her views, she may plausibly (especially at the start) be described as not (yet) having conscientious convictions. Of course, this does not mean that these beliefs are insignificant-they are preconditions of or precursors to conscientious convictions. We may even decide that these beliefs that fall short of the standard of conscientiousness are significant enough to be included within the protections or exceptions accorded to conscientious convictions. This, however, is not the same as saying that the standard of conscientiousness itself-which determines what counts as having conscientious convictions - is overly narrow and should be relaxed. See Delmas, "False Convictions and True Conscience," 409-10; and Harel, review of Conscience and Conviction.

34 Among others, see Smith, "The Burdens of Conviction," 694-97; and Coady, review of Conscience and Conviction, 502-3. 
While the counterexamples are intuitively plausible, the critics are mistaken in specifying the challenge they pose. Consider their claim that even though the agents in the counterexamples fail to satisfy one of the communicative conditions, they nonetheless actually have conscientious convictions. Whether these agents actually have conscientious convictions, however, is beside the point. Recall that our task concerns differentiating disobedients while lacking unmediated access to their internal states. The differentiation is to be secured from the perspective of their audience. From this perspective, an individual fails the differentiation demand when she fails to behave in ways that show others that she acts on the basis of conscientious convictions-even though she may actually have such convictions.

Given this, we should understand the counterexamples differently. They show that disobedients may succeed in showing others that they act on the basis of conscientious convictions despite their failure to satisfy one of the communicative conditions. This is because their actions satisfy enough of the (other) conditions such that observers may securely and confidently judge them as acting on the basis of conscientious convictions. The fact that we indeed make such judgments - and often confidently so-is, I take it, delivered by the critics' counterexamples. The counterexamples, then, are rightly a challenge to Indication, but not to Possession.

We may respond to this challenge to Indication in two ways. First, we may respecify the conditions so that they accurately pick out those who show that they act on the basis of conscientious convictions. That is, we may try to ensure that they are indeed the right necessary and sufficient conditions. While this may be a plausible option, it is not one I take here. I suggest that we choose, instead, to recharacterize the conditions. Following from earlier discussions, the most natural recharacterization of the conditions is that they delineate what is paradigmatically or typically true of those who successfully show others that they act on the basis of conscientious conviction-rather than what is necessary and sufficient for doing so. That is, we should understand Indication as outlining the paradigmatic conditions for showing others that one acts on the basis of conscientious convictions. Call this Indication* This is the first core aspect of my account. It responds to the challenge posed by the counterexamples not by weakening the specification of the conditions but by weakening how we characterize them.

There are at least two reasons to endorse Indication*. First, it allows us to sidestep the trade of counterexamples that is invited and facilitated by characterizing the conditions as necessary and sufficient. According to Indication*, the failure of an individual to satisfy one of the communicative conditions (or perhaps to meet all of them fully) does not automatically mean that she fails to show others that she acts on the basis of conscientious convictions. To reach that verdict, we must pay attention to the specifics. Among other things, we would have 
to examine whether she has satisfied the other conditions, and by how much; we would also have to engage in deliberations about whether her satisfaction of those other conditions allows us to judge her as having shown that she acts on the basis of conscientious convictions. This characterization, then, facilitates more nuanced discussions - an especially important payoff when we encounter borderline or vague cases. Second, Indication* is accommodating of imperfect beings like ourselves. Acting in ways that fail to satisfy just one of the conditions does not automatically mean that we fail to show others that we act on the basis of conscientious convictions. And insofar as being regarded as such is important for the protections or exceptions that are typically granted to conscientious disobedients, Indication* is more humane than Indication. ${ }^{35}$

Adopting Indication*, however, results in some vagueness in determining whether disobedients succeed in showing others that they act on the basis of conscientious convictions. In some borderline circumstances, Indication* may not even deliver any determinate answers. Here, my response is resolute-we should accommodate rather than eliminate this vagueness. We should not try to make our determination of who succeeds in showing others that they act on the basis of conscientious convictions seem clearer than it actually is. Doing so is concordant with the initial problem - that we do not have direct and unmediated access to the internal states of the actors whose actions we are tasked with evaluating. Moreover, given that we can confidently judge whether a disobedient acts on the basis of conscientious convictions despite her failure to satisfy every single one of the conditions, there appears to be little practical payoff in construing the conditions as necessary and sufficient.

\section{HOLISTIC ASSESSMENT}

According to Indication*, a disobedient who fails to satisfy one of the communicative conditions can nonetheless succeed in showing others that she acts on the basis of conscientious convictions. This leaves open the possibility that when such a disobedient engages in an act that fails to satisfy most or all of the conditions, she fails to show that she acts on the basis of those convictionsthus failing to satisfy the differentiation demand. In this section, I argue that this possibility should not bother us too much-in many cases, disobedients can

We might think that the reasons for endorsing Indication* also support a similar recharacterization of Possession-such that the conditions are paradigmatically satisfied by those who have conscientious convictions, rather than necessary and sufficient conditions for having such convictions. I do not take a stance on this issue here. I leave open the possibility that the conditions are indeed necessary and sufficient for having conscientious convictions. 
satisfy the differentiation demand even though their singular or occasional acts of disobedience may fail to satisfy most or even all of the conditions. This is the second core aspect of my account.

Consider a committed environmentalist, Aly, who dedicates a significant portion of her life to campaigning and activism and who generally behaves in ways that satisfy the communicative conditions in most areas of her life and political activity. On one occasion, she anonymously dumps pollutants into the waters at a beach that is much loved and frequented by the locals, intending to draw attention to and protest pollution and environmental degradation. Aly's action appears to violate all the communicative conditions. Her polluting act appears to be inconsistent with her stance against pollution. It seems to violate the universality condition insofar as she does something she thinks is wrong for others to do. The anonymity of her action clearly violates the non-evasion condition and plausibly also the dialogic condition. It appears that, in this case, Aly fails to show that she acts on the basis of conscientious convictions-and thus fails to differentiate herself from criminals.

Two related—and increasingly resolute-responses to this are available for the case of Aly (and those similar to it). First, we can challenge the claim that Aly's act violates all the communicative conditions. If this succeeds, we mitigate or even eliminate the doubts about whether she acts on the basis of conscientious convictions. This first response turns on a finer-grained description of the act. Aly may be concerned not about pollution and environmental degradation simpliciter but with the unequal distribution of burdens imposed by pollution and environmental degradation. She may decry the fact that the burdens of pollution and degradation are disproportionately borne by the most disadvantaged individuals in society (or in the world). This, as it turns out, is one of the most common claims made by environmental activists and disobedients. Aly's convictions may be more accurately and plausibly presented when they are understood as "fine grained" or specific, rather than "coarse grained" or general. If so, her act of polluting the beach-assuming it does not contribute to the pollution and degradation affecting the most disadvantaged—is concordant with what she stands for. ${ }^{36}$ She does not necessarily violate the consistency or universality conditions. Even if she remains anonymous to the public, the activist communi-

There are complications arising from indirect contribution-especially where and how to establish the threshold beyond which indirect contributions are to be considered as part of an act and thus feature in our descriptions and evaluations of the latter. These complications are not unique to my account; they are faced by accounts of disobedience more generally. They concern how we should set a threshold between two implausible extremes-one where all indirect contributions count and the other where no such contributions count. I do not address these complications here. 
ty of which she is part may take responsibility for her actions. If so, the act may not fail the non-evasion condition.

This response-which centers on how we describe disobedients' convictions-is often generalizable. ${ }^{37}$ One frequent criticism of disobedient actsespecially those that impose obvious and significant burdens on others-is that they represent everything the disobedients purport to stand against. For instance, disobedients whose actions result in property damage or harm to others are often described as behaving in ways that violate their convictions about protecting the interests of, or avoiding harm to, others-failing the consistency condition. They are often also described as granting themselves the license to engage in actions of the kind they protest-failing to satisfy the universality condition. In these cases, disobedients are often denounced as criminals on the basis of their engagement in these actions, based on the assumption that those whose disobedient acts are undergirded by conscientious convictions would not engage in them. Now, we see that the success of these criticisms in threatening the differentiation of disobedients from criminals actually turns on the unstated assumption that the commitments of the disobedients are most plausibly understood in general rather than specific terms. In many cases, this assumption is unwarranted. Among other things, even disobedients who participate in arson, rioting, vandalism, or vigilantism - actions that are most frequently regarded as mere criminality — can be understood as behaving in ways that are concordant with their concerns and commitments. Their destructive actions are typically neither random nor wanton, but directed at those who are complicit in bringing about the injustice against which they protest. ${ }^{38}$ Similar arguments have also been marshaled in defense of certain forms of vandalism and vigilantism. ${ }^{39}$

In sum, Aly's act (and those similar to it) may not actually violate most or all of the communicative conditions. If so-and drawing from our earlier discussions of Indication* - she may still succeed in showing that she acts on the basis of conscientious convictions and in differentiating herself from criminals. The first response reiterates the earlier caution: in describing and evaluating disobedients and their actions, we must pay attention to the specifics. However, this response leaves open the possibility of cases where the disobedient act in concern

For a recent and extensive study of how the interests of various groups and actors-including public officials, businesses, prosecutors, and other citizens-shape whether and how acts of dissent (including disobedience) are described as criminal activities, see Terwindt, When Protest Becomes Crime.

For representative texts, see Fogelson, "Violence and Grievances”; Waddington, "The Madness of the Mob?"; and Moran and Waddington, Riots. 
actually violates most or all of the communicative conditions. It appears that in committing such acts, the disobedient is undifferentiated from criminals. A further response is needed.

It may seem that a simple appeal to the broadly context-sensitive nature of the communicative conditions can help us to defend Aly's differentiation from criminals, even if she behaves in a way that violates most or all of the conditions. Recall that the satisfaction of the conditions does not have conclusive weight, especially relative to other considerations that may apply to any given disobedient. If so, the accommodation of context sensitivity means that the failure of a disobedient to meet most or even all of the communicative conditions does not necessarily indicate her lack of conscientious convictions. The appeal to context sensitivity is a resolute response insofar as it denies that we can make obvious or easy inferences that Aly lacks conscientious convictions on the basis of her actions that fail to satisfy most or all of the communicative conditions.

However, this response falls short of defending her. As we have seen earlier, whether a disobedient actually has conscientious convictions is beside the point. The demand facing disobedients is to differentiate themselves from criminals, given that observers do not have unmediated access to their mental states and thus need more than their mere assertions as reassurance that their disobedience is undergirded by their conscientious convictions. The reliance on their behavior is, in a sense, all that we have. The appeal to context sensitivity fails precisely where it is needed-it does not secure the claim that in violating most or all of the communicative conditions, Aly successfully shows others that she acts on the basis of conscientious convictions. Moreover, in accommodating the possibility that disobedients may not (and need not) behave in ways that satisfy the communicative conditions - which shows others that they act on the basis of conscientious convictions-we seem to return to the initial problem of having to rely on their assertions. In the context of Indication and Indication*, the specter is raised that the incorporation of context sensitivity "defeats the point of the communicative principle of conscientious conviction, which is to guarantee that the sincerity of our commitments be visible to all, and that no doubt be cast on it." ${ }^{40}$ A simple appeal to context sensitivity here may render the practical tests associated with satisfying the conditions pointless. ${ }^{41}$ I set it aside.

Delmas, "False Convictions and True Conscience," 411. Delmas does not appear to distinguish between Possession and Indication. My claim here is that the worry is apt for the latter and not the former.

41 This means that there is an unresolved internal inconsistency in Brownlee's account of the communicative principle of conscientiousness concerning Indication (but not Possession). Since my concerns are not exegetical, I set this issue aside. 
My second resolute response to the challenge posed by Aly's case begins from the recognition that the communicative conditions are a specification and elaboration of the more general differentiation demand. We are concerned with whether disobedients satisfy the conditions only because that is a way for us to determine if disobedients satisfy the differentiation demand. In recognizing this, however, we glimpse the possibility that a disobedient's satisfaction of the communicative conditions may come apart from her satisfaction of the differentiation demand. That is, she may fail at the former yet succeed in the latter. This, I suggest, is precisely so in the case of Aly.

To secure this claim, we need to adopt a holistic assessment of Aly and her act that violates most or all of the communicative conditions. Call this Holism. This is the second core aspect of my account. Holism covers two domains-the assessment of individuals and their actions. I discuss these in turn.

First, in our assessments of disobedients, we should look at their past and ongoing behavior in most or all areas of their lives, rather than simply looking at singular acts. ${ }^{42}$ In the case of Aly, we should not narrowly focus on the act that violates most or all of the communicative conditions. Instead, we should attempt to get a fuller view of her actions prior to and concurrent with that act. Here, we see that she has generally behaved in ways that satisfy the conditions in most other areas of her life and political activity. She has generally (and perhaps even plentifully) shown herself to act on the basis of conscientious convictions. This licenses our inference that even though Aly behaves in a way that fails to satisfy most or all of the communicative conditions in this case, she nonetheless acts on the basis of conscientious convictions. If this inference succeeds, her failure in this case does not threaten or eliminate her differentiation from criminals. More generally, disobedients can satisfy the differentiation demand even though they do not always behave in ways that satisfy most or all of the communicative conditions.

The holistic assessment of disobedients is intuitively plausible. We are typically reluctant to judge activists who have spent large parts of their lives acting on the basis of conscientious convictions as undifferentiated from criminals- those who do not act on the basis of such convictions-simply on the basis of their engaging in a single act that violates most or all of the communicative conditions. In practical terms, we typically can securely differentiate even a disobedient who engages in radical actions (such as arson, rioting, vandalism, or vigilantism) from criminals who do not act on the basis of conscientious convictions. The intuitive plausibility of holistic assessment extends to cases that are the reverse of Aly's.

42 Holism may even accommodate the retrospective differentiation of disobedients' past actions, on the basis of their subsequent actions or revelations. This possibility gives rise to complications that I do not address here. 
Consider a lawbreaker who has not shown that she acts on the basis of conscientious convictions in most or all areas of her life, but who, on one occasion, breaks the law in a way that satisfies all of the communicative conditions. She purportedly shows that in this case she acts on the basis of conscientious convictions. Despite this, we are likely to have serious suspicions about whether she truly acts on the basis of conscientious convictions. These suspicions, however, are unwarranted (and perhaps even unintelligible) if we focus only on the act itself. They are warranted only if we assess the lawbreaker holistically.

On a holistic assessment, disobedients' differentiation from criminals is threatened or even eliminated only when they have rarely or never behaved in ways that satisfy the communicative conditions, and thus rarely or never given any indications of their conscientious convictions prior to the act in concern (which fails to satisfy most or all of the communicative conditions). In such cases, however, it may not be problematic for us to adhere, even dogmatically, to the verdict delivered-that the disobedients in concern are not adequately differentiated (if at all) from criminals. Of course, this verdict may be mistakenthe disobedients may actually be acting on the basis of their conscientious convictions. But given that they have rarely or never behaved in ways that indicate their conscientious convictions-along with our having no unmediated access to their mental states and with our interests in not being strung along-even our dogmatism may be appropriate. Beyond these extreme and clear-cut cases, we would have to engage in nuanced discussions-concerning whether (and the extent to which) disobedients satisfy the other communicative conditions in other areas of their lives. Holism facilitates more nuanced discussions than an account that judges disobedients to be undifferentiated from criminals on the basis of singular acts that fail to satisfy most or all of the conditions. While this point may seem obvious, it is not often heeded in public and philosophical discourse. ${ }^{43}$ Commentators are often quick to denounce disobedients as criminals based on one or a few of the actions that they engage in - disregarding the relevance and significance of their previous behavior.

The main upshot of a holistic assessment of individuals is that it reveals that our concern with acts of disobedience that violate most or all of the communicative conditions really matters only in borderline cases, where the violations threaten or eliminate the differentiation between a disobedient and a criminal. In many cases, whether any given act of disobedience violates most or all of the conditions is likely to be immaterial for the purposes of differentiation. We 
should not exaggerate the importance of any given act of disobedience for the differentiation of disobedients from criminals.

The second domain that Holism covers concerns acts of disobedience. Without this, Holism would be implausibly permissive. This is because the holistic assessment of disobedients does not appear to set restrictions on what exactly disobedients can do. Here, the worry is that some acts that fail to satisfy most or all of the communicative conditions are worse than others. An act of pollution intuitively appears to be significantly different from one of terror bombing in terms of how they affect the differentiation of their perpetuators from criminals - even if they both similarly violate most or all of the conditions.

Here, we should look at whether a given act of disobedience can be understood as part of a disobedient's broader project to live in accordance with her convictions, or to bring about conditions in which she can do so. It is only when the act cannot be understood in this way-when it has no discernible connections to any broader projects - that the worry about the disobedient's differentiation has bite. Otherwise, the radical nature of the act does not threaten or eliminate the disobedient's differentiation from criminals.

Holism helps us to accommodate acts of disobedience that are radical because of the contexts in which disobedients find themselves. ${ }^{44}$ Disobedients' deliberations about their political action (including, but not limited to, disobedience) are complicated. They have to weigh up a range of complex and interconnected considerations salient in the contexts in which they operate. Among other things, these may pertain to the relationship between the disobedients and their audience, the expected reactions of other citizens and public officials, the expected responses from and implications for other activist groups, the organization of the media, the possibility of publicizing their act without distortion, and so on. Disobedients may find themselves in a society that has repeatedly ignored or dismissed their previous acts of legal protests or their constrained disobedience. Or they may find themselves in a society plagued by injustices so severe and urgent that legal protests or constrained disobedience would be pointless. In these contexts, disobedients may have no other choice than to engage in what are regarded as radical acts if they wish to make any advances in their broader projects. According to Holism, as long as these acts can be seen as part of disobedients' broader projects, the fact that they are radical neither threatens nor eliminates the disobedients' differentiation from criminals.

A simplified example (which centers on the relationship between an actor

44 For a discussion of how some prosecutors and legal systems describe and evaluate disobedient actions in a way that ignores the broader context in which they are carried out, and the problems accompanying that approach, see Terwindt, When Protest Becomes Crime, 56-65. 
and her audience) illustrates the point. Suppose that Betty has just discovered that her housemate, Charlie, has stolen money from her to pay for recreational drugs and that this is not the first time that Charlie has done this. Betty has tried, by having conversations with him on several occasions, to gently persuade Charlie to stop. Suppose that Betty now breaks into Charlie's room and steals his belongings - to teach him a lesson about the impact and invasiveness of theft. In her anger, she also damages some of Charlie's belongings. We can plausibly suppose that Betty's actions, while understandable, are drastic and radical. In this case, would we say of Betty that she is therefore undifferentiated from a criminal who behaves similarly? I do not believe so. Betty stands in a relationship to Charlie and has tried to engage Charlie in milder ways. Her current actions, while drastic, make sense as a constituent of a bigger project-of getting Charlie to change his behavior. The same cannot be said for the criminal who breaks into Charlie's room and does exactly the same things. This point is extendable to the case of disobedients who engage in radical acts of disobedience.

Two clarifications are in order. First, my claim is that disobedients who engage in radical acts are not, simply on the basis that those acts are radical, therefore undifferentiated from criminals. I do not claim here that such radical acts are justified or permissible. We may have several serious reservations about Betty's actions and, by extension, those of disobedients who engage in radical acts. These may have to do with the fact that they may be unnecessary, disproportionate, or aimed at the wrong targets, among others. Indeed, our recognition that disobedients are securely differentiated from criminals is compatible with our directing harsh criticisms at, or flatly rejecting, their actions. What we cannot do, however, is to criticize and reject those actions on the basis that their radical characters render the disobedients no different from criminals.

Second, we must not adopt an overly restrictive view of whether and how an act can be seen as part of a disobedient's broader project. Radical acts are often viewed negatively. Among other things, they are criticized for being ineffective for achieving the disobedient's goals or counterproductive to the achievement of those goals. It may be thought that ineffective and counterproductive actions cannot be understood as part of a disobedient's broader project. This, however, is a mistake. Acts of disobedience that are often touted as ineffective or counterproductive may actually serve goals that critics have missed..$^{45}$ Among other things, disobedients are also interested in generating publicity, starting discussions, sparking and sustaining interests, building solidarity with other activists,

45 It has been argued that radical acts are not necessarily ineffective or counterproductive. For further discussion (though under the classification of "uncivil" acts), see Delmas, A Duty to Resist, 58-67. 
or simply challenging everyday practices. ${ }^{46}$ An action that is ineffective or counterproductive with regard to one goal may instead serve other goals. We must be cautious on two issues. We must not assume that one goal (or a subset of them) is the most fundamental, and the only goal against which the assessments of the effectiveness or counterproductivity of acts are to be made. Moreover, even if there were indeed one fundamental goal — and one that is endorsed by the disobedients themselves - we must not assume that disobedients must always act in ways that directly and immediately serve that goal.

The discussions in this section pose a serious challenge to the views-common in much philosophical and public discourse-that the radical quality of certain actions on its own throws doubt on whether the disobedients in concern act on the basis of conscientious convictions, and that radical acts automatically render their perpetuators equivalent to criminals. Actions that are typically regarded as radical in these ways include arson, rioting, vandalism, or vigilantism, among others. On my account, we see that these views are critically incomplete. We must not fixate on the radical quality of the actions. We must also look at the actors and the context in which the actions are situated. Holism provides a conditional defense of radical action. Insofar as the disobedients who engage in radical actions have generally shown that they act on the basis of their conscientious convictions, and insofar as their act can be seen as part of a broader project to which they are committed, the radical character of their act does not threaten or eliminate their differentiation from criminals. It is only when they fail either of the conditions that their differentiation is threatened. ${ }^{47}$ In practical terms, adopting Holism means that disobedients are securely differentiated in a broad range of cases - even for radical acts that are typically equated with criminality.

\section{CONSTRAINING DISOBEDIENTS}

In the preceding sections, I have argued that we should not narrowly focus on whether acts of disobedience satisfy the communicative conditions. Instead, we should also examine whether those acts can be understood as part of disobedients' broader projects and whether the disobedients have provided adequate indication that they act on the basis of conscientious convictions. In this section, I consider two related objections, both of which center on the worry that my account imposes overly stringent constraints on disobedients.

My defense of acts of disobedience that fail to satisfy most or all of the 
communicative conditions rests on the claim that insofar as disobedients have provided ample indication that they act (or have acted) on the basis of conscientious convictions in other areas of their lives, their failure to satisfy the conditions in any given case does not threaten or eliminate their differentiation from criminals. This may be thought to entail a severe constraint on disobedients. They have to ensure that their past and ongoing behavior in other areas of their lives-leading up to their acts of disobedience-provides adequate indication that they have and act on the basis of conscientious convictions. Not just anyone can engage in lawbreaking political action while simultaneously satisfying the differentiation demand. In many cases, we may find that disobedients have failed to meet this severe constraint, and thus that my account would unfairly treat them as undifferentiated from criminals. For example, individuals who are not ordinarily social justice activists appear to be undifferentiated from criminals if they participate in large-scale disobedience protesting injustice.

Several considerations mitigate the apparent severity of this constraint. First, the differentiation demand is not the most important demand on political disobedience or action. In some circumstances, satisfying the differentiation demand may take a back seat to the need to mitigate or eliminate serious injustices. In these cases, there may be good reason for individuals to behave disobediently, even in the knowledge that they may not be differentiated from criminals.

Second, what we are asking of disobedients is simply that they show others, in other areas of their lives beyond their disobedience, that they indeed have and act on the basis of their own conscientious convictions. These are convictions that - if disobedients indeed possess them-are among the most fundamental and central in their importance to the disobedients in concern. ${ }^{48}$ Individuals with such convictions aim, typically, to behave in ways that preserve their integrity. ${ }^{49}$ Given this, even the requirement that they live in accordance with their deepest convictions, as far and as often as is possible, does not strike me as implausible. Of course, we must make room for context sensitivity in our assessments of whether any given disobedient has behaved in this way in other aspects of her life. We should take seriously and try to accommodate the possibilities, discussed earlier, that in some circumstances the burdens associated with living in accordance with one's conscientious convictions may be too onerous.

That being said, and third, we should take an ecumenical view of what counts as doing enough to indicate one's conscientious convictions. Insofar as conscientious convictions are deeply important to individuals_-including, among other things, structuring how those individuals see and interact with the world-we

48 Brownlee, Conscience and Conviction, 7.

49 McCloskey, "Conscientious Disobedience of the Law," 537. 
should and can expect that they are shown even through these individuals' mundane and ordinary actions. More concretely, we can say that activities such as the following should be regarded as providing indication that an individual acts on the basis of her conscientious convictions: participating in or contributing to activist organizations or events, attending teach-ins or other lectures, attempting to engage in conversations with or convert others to one's cause (which can include, at the seemingly most trivial, conversations on social media), and signing and circulating petitions, among others. We should neither think nor require that disobedients only indicate their conscientious convictions when they engage in high-stakes activities. ${ }^{50}$

While ecumenical, this constraint is not toothless. Among other things, individuals who participate in lawbreaking activity on impulse without having provided adequate indication of their conscientiousness in other aspects of their lives would be judged as insecurely differentiated (if at all) from criminals. In these cases, we want them to do more than they have done to show (or show more clearly) that they indeed have and act on the basis of conscientious convictions.

The second objection is that my account delivers the wrong result in the cases of disobedients who have recently changed their conscientious convictions - "converts"- and who act on the basis of their newfound convictions. In such cases, my account appears to incorrectly judge-especially on the basis of their previous behavior - that converts are not conscientious. Consider, for instance, an individual who has not previously behaved in any ways that indicate her conscientious convictions. Suppose that she now possesses strong conscientious convictions about police brutality and violence and proceeds to engage in a radical act of disobedience (perhaps anonymously setting fire to a police station). Here, it seems that on the basis of Holism she faces insurmountable difficulties in showing others that she does act on the basis of her conscientious convictions. She is wrongly picked out as undifferentiated from a criminal, when in fact she has and acts on the basis of conscientious convictions.

Iris Murdoch puts the point beautifully:

When we apprehend and assess other people we do not consider only their solutions to specifiable practical problems, we consider something more elusive which may be called their total vision of life, as shown in their mode of speech or silence, their choice of words, their assessments of others, their conception of their own lives, what they think attractive or praise-worthy, what they think funny: in short, the configurations of their thought which shows continually in their reactions and conversation. These things, which may be overtly and comprehensibly displayed or inwardly elaborated and guessed at, constitute what ... one may call the texture of a man's being or the nature of his personal vision. (Hepburn and Murdoch, "Symposium," 39) 
While this is a serious problem, two considerations mitigate its sting. First, changes in deep convictions do not usually happen overnight. They typically take time to develop. Their development is also typically facilitated by interactions and conversations with others. Conscientious convictions do not, as it were, "leap as Athena did full-grown and armed from Zeus's head." ${ }^{11}$ If so, there may well be plenty of opportunities for the convert to behave in ways that indicate her changed (or changing) convictions. Taken together with the ecumenical view of what counts as doing enough to indicate one's conscientious convictions, this allows my account to pick out even fairly recent converts. ${ }^{52}$ Second, if such opportunities are rare, we may reasonably be resolute in our skepticism that the convert has and acts on the basis of her conscientious convictions and in our belief that she may not be adequately differentiated (if at all) from criminals. This is connected to the very problem we began with that motivates the differentiation demand - that we do not have unmediated access to others' internal states and that we have interests in avoiding being strung along. While this resoluteness is unsatisfactory-it does not guarantee extensional accuracy-it appears to be a more general problem with attempting to secure differentiation from the perspective of one's audience. The hope, then, is that in light of the first consideration, the circumstances in which we have to stand resolute are few and far between.

\section{CONCLUSION}

Conscientious disobedients face the demand to differentiate themselves from criminals whose actions also violate laws but are not undergirded by conscientious convictions. In public and philosophical discourse-though with different levels of sophistication - conscientious disobedients are often criticized on the basis that their actions render them no different from criminals. In this essay, I have argued otherwise, by articulating and defending the claim that disobedients who engage in radical acts of disobedience may still be securely differentiated from criminals. The category of conscientious disobedients is potentially more inclusive than has been commonly assumed within public and philosophical discourse. We have reason to revise our judgments and treatments of such disobedients.

51 Harel, review of Conscience and Conviction.

52 This might not be enough for us to accurately pick out those individuals who in fact have sudden and radical transformations in their conscientious convictions-perhaps and especially of a religious sort. Here, and in light of how the differentiation demand has been specified, I am inclined to take the resolute response I discuss presently. Alternative ways of specifying the differentiation-such as that given by Arendt in Crises of the Republic-may well avoid this problem, albeit incurring other costs. 
The main upshot of my account is that it significantly reframes what the salient questions are when we are confronted with disobedience. Rather than narrowly focus on acts of disobedience that are committed, we must also direct our attention to the disobedients themselves and the contexts in which the acts are committed. On my account, the differentiation demand can be satisfied even by disobedients who engage in what are typically regarded as radical actions. In practical terms, this means that even disobedients who engage in actions such as arson, rioting, vandalism, or vigilantism can also successfully differentiate themselves from criminals. We should be much less eager to denounce conscientious disobedients on the basis of their engagement in this or that action, and we must pay more attention to other aspects of their lives and actions. I believe that this account best vindicates the claims - made by many disobedients - that even their radical actions are undergirded by conscientious convictions and that they are not criminals. $^{53}$

\section{Stanford University and Nanyang Technological University cm.lim@ntu.edu.sg}

\section{REFERENCES}

Arendt, Hannah. Crises of the Republic. New York: Harcourt Brace, 1969.

Beinart, Peter. "Left Wing Protests Are Crossing the Line." The Atlantic, November 16, 2018. https://www.theatlantic.com/ideas/archive/2018/11/protests -tucker-carlsons-home-crossed-line/576001.

Bejan, Teresa M. Mere Civility. Cambridge, MA: Harvard University Press, 2017. Brennan, Jason. When All Else Fails: The Ethics of Resistance to State Injustice. Princeton: Princeton University Press, 2018.

Brownlee, Kimberley. Conscience and Conviction: The Case for Civil Disobedience. Oxford: Oxford University Press, 2012.

. "Reply to Critics." Criminal Law and Philosophy 10, no. 4 (December 2016): 721-39.

Celikates, Robin. "Rethinking Civil Disobedience as a Practice of Contesta-

53 I am grateful for comments from and discussions with Yuna Blajer de la Garza, Kimberley Brownlee, Daniel Butt, Kathleen Creel, Cécile Fabre, Kailing Fu, Abby Jaques, Dongxian Jiang, Todd Karhu, Geoff Keeling, Nannerl Keohane, Desiree Lim, Anne Newman, Avia Pasternak, Joseph Raz, Rob Reich, Thomas Simpson, Alicia Steinmetz, Zofia Stemplowska, Lee Wilson, Jonathan Wolff, the audiences at Ockham Society (Oxford, 2018), and two anonymous reviewers for this journal. 
tion-Beyond the Liberal Paradigm." Constellations 23, no. 1 (March 2016): $37-45$.

Coady, C.A.J. Review of Conscience and Conviction: The Case for Civil Disobedience, by Kimberley Brownlee. Journal of Value Inquiry 50, no. 2 (June 2016): 501-6.

Cochrane, Emily. "Sarah Huckabee Sanders Was Asked to Leave Restaurant over White House Work." New York Times, June 23, 2018. https://www.nytimes. com/2018/o6/23/us/politics/sarah-huckabee-sanders-restaurant.html.

Cowley, Christopher. "Conscientious Objection and the Limits of Dialogue." Philosophy and Social Criticism 42, no. 10 (December 2016): 1004-14.

Davis, Angela. "Race and Criminalization: Black Americans and the Punishment Industry." In The House That Race Built: Original Essays by Toni Morrison, Angela Y. Davis, Cornel West, and Others on Black Americans and Politics in America Today, edited by Wahneema Lubiano, 264-79. New York: Random House, 1997.

Delmas, Candice. A Duty to Resist: When Disobedience Should Be Uncivil. Oxford: Oxford University Press, 2018.

- "False Convictions and True Conscience." Oxford Journal of Legal Studies 35, no. 2 (Summer 2015): 403-25.

Estlund, David M. "Deliberation Down and Dirty: Must Political Expression Be Civil?" In The Boundaries of Freedom of Expression and Order in American Democracy, edited by Thomas R. Hensley, 49-67. Kent, оH: Kent State University Press, 2001.

Fogelson, Robert M. "Violence and Grievances: Reflections on the 1960s Riots." Journal of Social Issues 26, no. 1 (Winter 1970): 141-63.

Harcourt, Bernard. "The Politics of Incivility." Arizona Law Review 54 (January 2012): 345-73.

Harel, Alon. Review of Conscience and Conviction: The Case for Civil Disobedience, by Kimberley Brownlee. Notre Dame Philosophical Reviews. February 29, 2013. https://ndpr.nd.edu/reviews/conscience-and-conviction-the-case-for-civil -disobedience/.

Hepburn, R.W., and Iris Murdoch. "Symposium: Vision and Choice in Morality." Aristotelian Society Supplementary Volume 30 (1956): 14-58.

Hill, Thomas E. "Conscientious Conviction and Conscience." Criminal Law and Philosophy 10, no. 4 (December 2016): 677-92.

Kapelner, Zsolt. "Revolution against Non-Violent Oppression." Res Publica 25, no. 4 (November 2019): 445-61.

Lim, Chong-Ming. "Vandalizing Tainted Commemorations." Philosophy and Public Affairs 48, no. 2 (Spring 2020): 185-216. 
Lovell, Jarret S. Crimes of Dissent: Civil Disobedience, Criminal Justice, and the Politics of Conscience. New York: New York University Press, 2009.

McCloskey, H.J. "Conscientious Disobedience of the Law: Its Necessity, Justification, and Problems to Which It Gives Rise." Philosophy and Phenomenological Research 40, no. 4 (June 1980): 536-57.

Moran, Matthew, and David P. Waddington. Riots: An International Comparison. London: Palgrave Macmillan, 2016.

Osterweil, Vicky. In Defense of Looting: A Riotous History of Uncivil Action. New York: Bold Type Books, 2019.

Pasternak, Avia. "Political Rioting: A Moral Assessment." Philosophy and Public Affairs 46, no. 4 (Fall 2018): 384-418.

Rawls, John. A Theory of Justice. Rev. ed. Cambridge: Belknap Press, 1999.

Sarat, Austin, ed. Civility, Legality, and Justice in America. Cambridge: Cambridge University Press, 2014.

Scott, James C. Weapons of the Weak: Everyday Forms of Peasant Resistance. New Haven: Yale University Press, 1985.

Smith, William. "The Burdens of Conviction: Brownlee on Civil Disobedience." Criminal Law and Philosophy 10, no. 4 (December 2016): 693-706.

Swaine, Jon, Ben Jacobs, and Paul Lewis. "Baltimore Protests Turn into Riots as Mayor Declares State of Emergency." Guardian, April 28, 2015. https:// www.theguardian.com/us-news/2015/apr/27/baltimore-police-protestersviolence-freddie-gray.

Terwindt, Carolijn. When Protest Becomes Crime: Politics and Law in Liberal Democracies. London: Pluto Press, 2020.

Thompson, Christie. “Hacktivism: Civil Disobedience or Cyber Crime?” ProPublica, January 18, 2013. https://www.propublica.org/article/hacktivism -civil-disobedience-or-cyber-crime.

Waddington, David. “The Madness of the Mob? Explaining the 'Irrationality' and Destructiveness of Crowd Violence." Sociology Compass 2, no. 2 (March 2008): 675-87.

Walzer, Michael. Political Action: A Practical Guide to Movement Politics. Chicago: Quadrangle Books, 1971.

Young, Iris Marion. "Activist Challenges to Deliberative Democracy." Political Theory 29, no. 5 (2001): 670-90. 